Chirurgia (2018) 113: 826-836

No. 6, November - December Copyright $\odot$ Celsius

http://dx.doi.org/10.21614/chirurgia.113.6.826

\title{
Symptomatic Stenosis after Laparoscopic Sleeve Gastrectomy - Incidence and Management in a High-Volume Bariatric Surgery Center
}

\author{
Florin Turcu, Cristian Balahura, Ionut Doras, Alina Constantin, Catalin Copaescu
}

Ponderas Academic Hospital Bucharest, Romania

Corresponding author:

Catalin Copaescu, MD PhD

Associated Professor of Surgery

Ponderas Academic Hospital

Nicolae Caramfil Street, no. 85 A

district 1, Bucharest, Romania

E-mail: catalin.copaescu@ponderas-ah.ro

\section{Abbreviations:}

LSG: Laparoscopic sleeve gastrectomy;

SS: Symptomatic Stenosis;

IRB: Institutional review board;

GEJ: gastro-esophageal junction;

UGl: upper gastrointestinal;

POD: postoperative day;

PF: posterior and lateral fixation

\section{Rezumat \\ Stenoza simptomatică după gastrectomia longitudinală - incidentă si tratament într-un centru de excelență în chirurgia bariatrică}

Introducere: Consecutiv utilizării extinse a gastrectomiei longitudinale (GL) ca procedeu de chirurgie metabolică, o complicație rară precum stenoza simptomatică (SS) e tot mai des întâlnită. Scopul studiului este de a stabili care este incidența şi tratamentul optim pentru SS după GL.

Metode: Au fost analizate toate cazurile cu SS după GL tratate în Ponderas Academic Hospital în perioada 2011 - 2018. Datele au fost extrase retrospectiv dintr-o bază de date menținută prospectiv. Laparoscopia sau/şi endoscopia au fost utilizate pentru a tratat stenozele organice sau functionale. Au fost analizate complicatiile şi eficiența tratamentelor aplicate.

Rezultate: Dintr-un total de 4304 GL un număr de 47 (1,1\%) pacienti au prezentat SS. Se adaugă la analiză 4 cazuri trimise din alte spitale. Chirurgia a fost prima optiune terapeutică în 9 cazuri, însă rata de success a fost doar $33 \%$. În 46 cazuri adresate endoscopiei au fost practicate 79 de dilatații endoscopice $(1.7 \pm 1.1$ per pacient). Este consemnată o perforație gastrică, fără alte complicații sau decese. Rata de urmarire la distanță a fost de 93,5\%. In ansamblu, rata de succes a procedelor endoscopice a fost de $90.7 \%$. Concluzii: Incidența SS după LSG este redusă. Dilatarea pneumatică este un procedeu sigur şi eficient şi trebuie să fie prima optiune terapeutică.

Cuvinte cheie: gastric sleeve stenosis, over-sewing the stapled line, gastric twist, endoscopic dilatation 


\section{Abstract}

Background: Owing to the increased use of laparoscopic sleeve gastrectomy (LSG) as a metabolic procedure, a rarely associated complication, the Symptomatic Stenosis (SS) will be more often encounter. The objective of this study is to establish a safe and effective management of SS after LSG.

Methods: We have analyzed all the patients with SS after LSG treated in Ponderas Academic Hospital from 2011 to 2018 . The information was retrospectively extracted from a prospectively maintained database. Laparoscopy and/or endoscopy were used to treat the organic or functional SS. The procedure's outcomes (effectiveness and complications) were analyzed.

Results: Out of the 4304 patients with LSG 47 (1.1\%) patients were identified with SS after LSG. The incidence is depending on the LSG technique. Other 4 patients referred to our center have been added. Surgery was the first choice in 9 cases with only $33.3 \%$ success rate. For the 46 patients referred to endoscopy there have been 79 pneumatic dilation with an average of $1.7 \pm 1.1$ per patient. We have encountered 1 perforation but any hemorrhage or death. Follow-up rate was 93.5\%. Over all, the success rate of endoscopic dilatations was $90.7 \%$.

Conclusion: The incidence of SS is low. Endoscopic pneumatic dilation is a safe and effective procedure and should be the front line choice in the management of SS after LSG.

Key words: gastric sleeve stenosis, over-sewing the stapled line, gastric twist, endoscopic dilatation

\section{Introduction}

Laparoscopic sleeve gastrectomy (LSG) has recently become the most popular metabolic surgery procedure in Europe and USA (1). LSG is considered a safe and effective option for the management of morbid obesity, with a low rate of associated postoperative complications $(2,3)$. One of these complications is the obstructive one and we have focused on those cases with significant clinical impact to the patient, defined as Symptomatic Stenosis (SS).

There is a wide range of proposed therapeutic solutions for SS starting with observations and nutritional support, to endoscopic procedures (dilation with through-the-scope balloons, achalasia balloons or self-expandable stents) $(4,5)$ and surgery including laparoscopic seromyotomy (6) or conversion to gastric by-pass (7).

The purpose of this study is to establish a safe and efficient management of SS after LSG with no improvement after conservative treatment.

\section{Materials and Methods}

All the patients presenting SS after LSG treated in Ponderas Academic Hospital from May 2011 to September 2018 were included into the present study. Patients with SS after LSG operated in other institutions and referred to our center were also included in the present study. The information was retrospectively extracted from a prospectively maintained database of our Bariatric Surgery Center of Excellence, after obtaining the approval of the Institutional review board (IRB). All the included patients were clinically presenting obstruction symptoms. Imaging and endoscopic details, as well information about the surgical/endoscopic intervention, time to diagnosis, resolution of symptoms, and stricture characteristics were available to all the patients.

\section{The Surgical Technique}

A standard preoperative bariatric workup was applied to all the LSG patients (8). Additional preoperative investigations were indicated based on individual patient comorbidities. An informed consent was signed by all the patients. LSG was performed in a standard French position, under general anesthesia, 
using five to six laparoscopic access ports. A Ligasure $^{\mathrm{TM}}$ vessel sealing device (Medtronic, USA) or a Harmonic Scalpel (Ethicon EndoSurgery, USA) were used for the devascularization of the entire greater curvature of the stomach. The gastric resection was carried out from 1 to $2 \mathrm{~cm}$ from the pylorus to the His' angle, $1 \mathrm{~cm}$ away from the gastro-esophageal junction (GEJ), by using linear staplers and a $35-\mathrm{Fr}$ calibration bougie, aiming a low capacity gastric tube $(60-80 \mathrm{ml})$. No buttress material was used for the stapled line. Two metallic clips were placed at on the upper extremity of the stapled line to mark radiologically the level of GEJ. A nasogastric tube used for gastric decompression and an $18 \mathrm{Fr}$ drainage tube siding the stapled line were left in place for the first 24 postoperative hours.

\section{Modifications of the Technique}

Three distinct stages are to be mentioned from the surgical technique perspective in our series. From 2011 to 2012, no fixation to the intraabdominal structures or treatment of the stapled line other than the bleeding control with Titanium ML clips were used. A systematic posterior and lateral fixation $(\mathrm{PF})$ to the prepancreatic fascia of the gastric tube was routinely introduced in 2013 (stage 2), and it was respected to all the patients. On the third stage, from 2014 to 2018, the stapled line was routinely over-sewn with 3.0 polypropylene running suture on its entire length. $\mathrm{PF}$ was used on the $3^{\text {rd }}$ stage, too.

During the postoperative course the oral intake was limited to clear liquids diet for all the patients. Gastrografin ${ }^{\circledR}$ upper gastro-intestinal (UGI) radiologic study was performed in the postoperative day (POD) 2, at 3, 6, and 12 months and yearly after, at the follow-up visits. Postoperative endoscopy was performed at 6 and 12 months and yearly after. The patients were discharged in the POD3.

\section{Symptomatic Stenosis Patients}

All the patients presenting postoperative food intolerance, dysphagia, nausea and/or vomiting, were referred to a UGI Rx study, for confirmation and better understanding of the obstruction etiology.

The transitory early postoperative obstructions encountered within the first week after LSG were not included into this study. The restriction of any oral intake, administration of PPIs (80-120 $\mathrm{mg}$ /day), administration of i.v. fluids and corticoids were very efficient in almost all the cases. However, if no clinical and radiological improvement was seen within several days, the patient was referred to UGI endoscopy.

The stenosis was considered organic if the endoscope could not pass through the radiological diagnosed stenosis while a functional obstruction was mentioned when the gastroscope could advance distally.

A computer tomography scan with 3D reconstruction of the esophagus and the stomach was also used to assess the eso-gastric surgical anatomy. Any twist or a kinking of the gastric tube or any mediastinal migration of the cardia through the diaphragmatic hiatus are noted.

The patients were considered to have an early presentation if the SS occurred within the first 3 postoperative months while a late presentation was considered if the time from LSG was greater than 3 months.

\section{Interventional Therapies Used for SS}

Laparoscopic surgery was used for acute situations, aiming to eliminate the digestive obstruction or for late organic stenosis, performing seromyotomies or revisions to Roux en Y Gastric Bypass.

However, for majority of the patients, the endoscopic approach was our first procedure of choice. If the patient was eligible for pneumatic dilation, UGI endoscopy was carried out under Propofol sedation.

In the cases of organic stenosis we preferred to start with through-the-scope balloons (18-20 mm diameter), in order to better control of the procedure under direct vision (Fig. 1).

A self expandable metallic stent (SEMS) to correct the intractable gastric stenosis associated postoperative leak after LSG was used in limited cases (Fig. 2). 

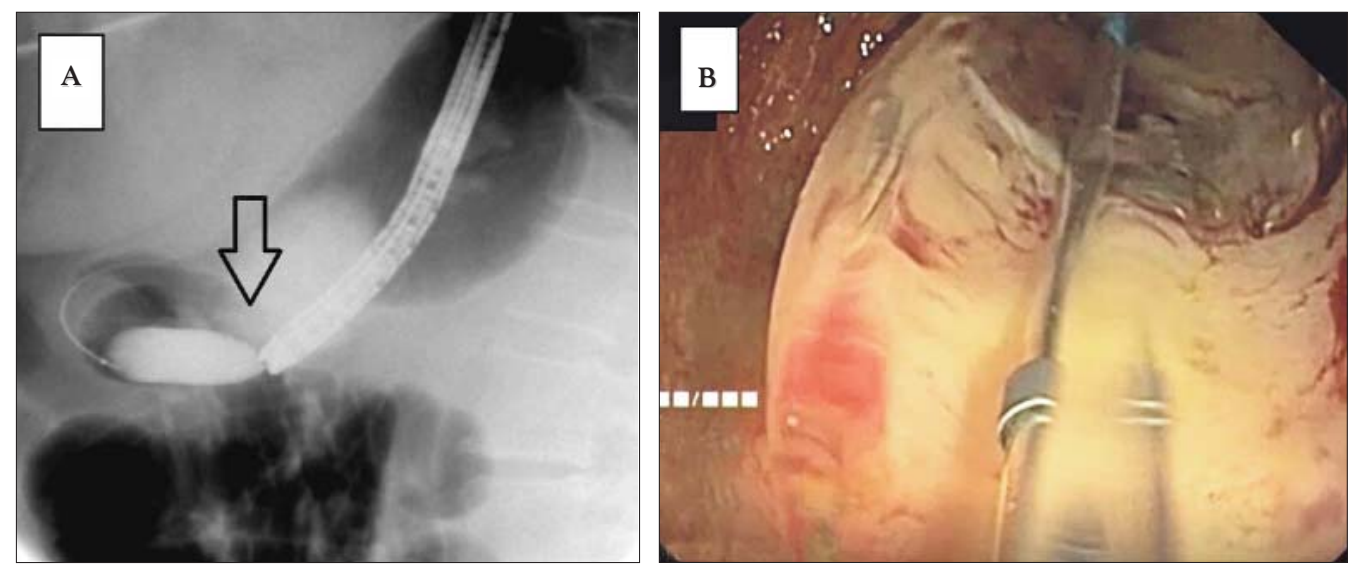

Figure 1. Endoscopic dilatation for organic stenosis of the gastric tube after LSG. (A) Radiologically guided positioning of the through-the-scope balloon; (B) endoluminal visual control of the endoscopic dilatation with through-the-scope balloon
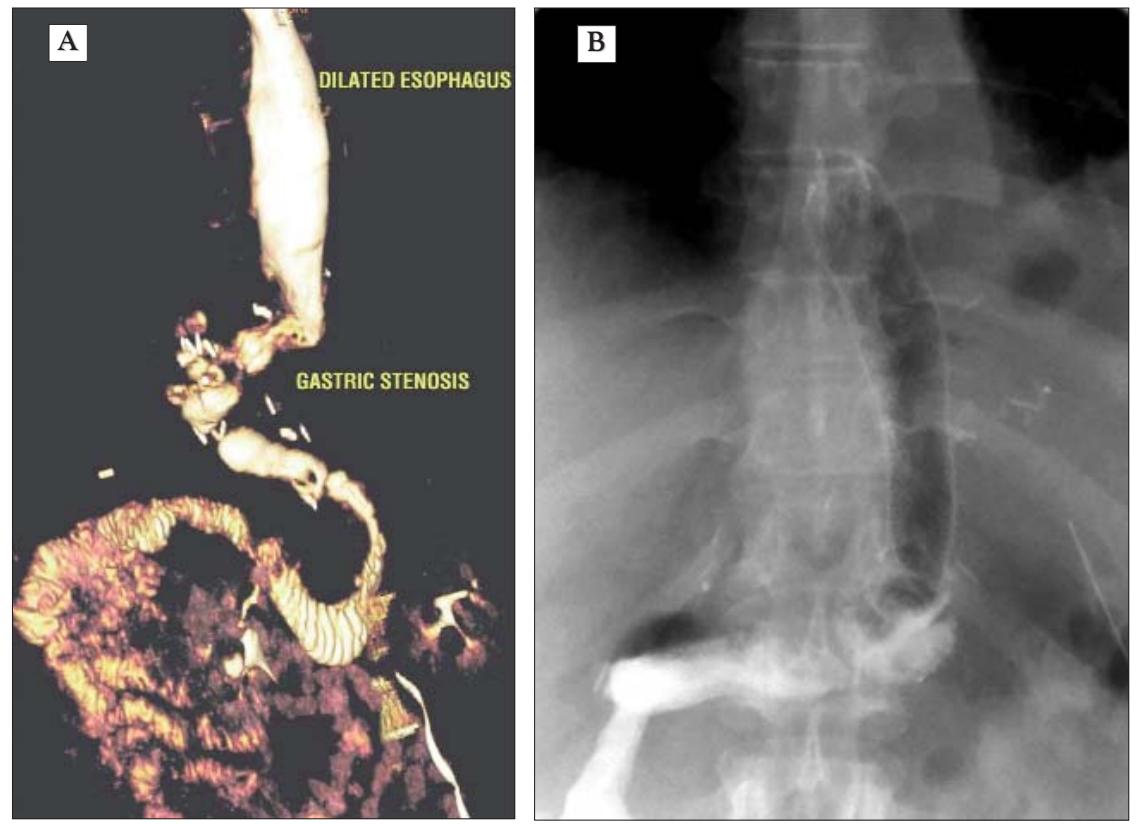

Figure 2. Gastric sleeve stenosis associated with postoperative leak after Laparoscopic Revisional surgery for converting Gastric Banding to Sleeve in two stages. (A) CT 3D reconstruction. Evidence for the gastric stenosis and the dilatated esophagus. (B) Upper GI Radiological Study after endoscopic placement of a self expandable metallic stent (SEMS)

In the cases of functional stenosis, the endoscope was advanced through the gastric tube into the duodenum, passing the pylorus. The length of the stricture and of the entire distorted segment was evaluated. A Savary guide wire was passed through the endoscope far distally, into the duodenum. The endoscopic dilation was performed under fluoroscopic guidance, starting with a $30 \mathrm{~mm}$ achalasia balloon inserted on the guide wire and inflated under radiological control, for 60 seconds (Fig. 3). The process was repeated at different stenotic levels aiming to break the perigastric adherences and gastric wall scars, targeting to reverse the gastric tube twist or obstruction. The functional result was radiologically assessed 

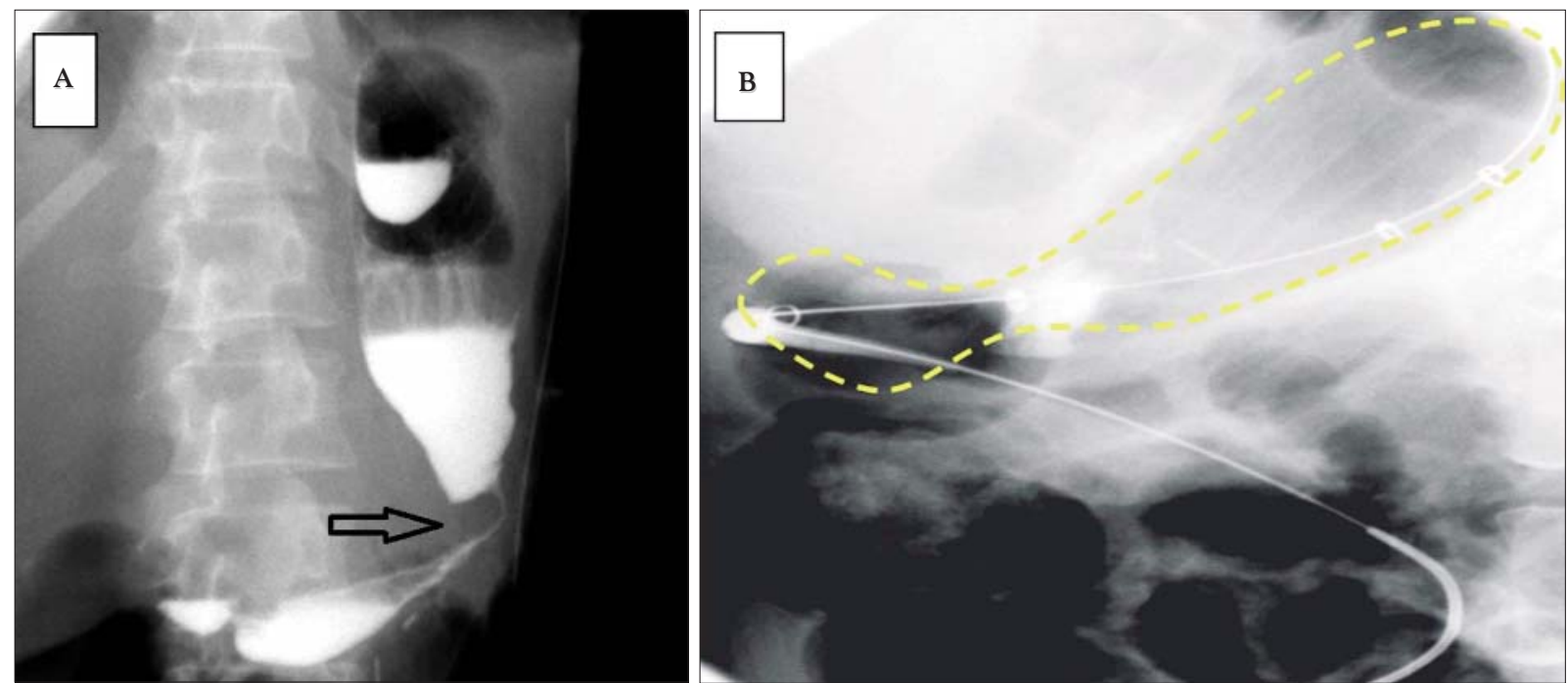

Figure 3. Functional stenosis after LSG. (A) radiological aspect of the incisura angularis obstruction. (B) endoscopic dilatation using achalasia balloon under fluoroscopic guidance

by an UGI Rx Gastrografin ${ }^{\circledR}$ study. The dilation was repeated at 2 to 4 weeks if needed.

The procedure's outcomes (effectiveness and complications) were analyzed. The resolution of the symptoms after the procedure (surgical or endoscopic) was considered a good result. Failure of the surgical approach was defined as the need for further endoscopic or surgical revision. Failure of the endoscopic approach was defined as the need for surgical revision.

Revision to Roux en Y Gastric By-pass was indicated for retractable obstruction and, for the patients with associatedgastro-cutaneousfistula a laparoscopic Roux en Y Fistulojejunostomy was performed.

The follow up was measured from the last pneumatic dilation to the last clinical or endoscopic control in our hospital.

Basic statistics were used to summarize patient demographics. The analysis program used was Microsoft Excel 2016 (Microsoft, Redmond, WA, USA)

\section{Results}

A total of 4304 patients underwent LSG in Ponderas Academic Hospital from May 2011 to September 2018. Revisional surgery, as a meaning of performing sleeve after previously performed LSG (re-sleeve) or gastric banding, was encountered in $1.8 \%$ (80 cases).

There were identified $47(1.1 \%)$ patients presenting SS after sleeve gastrectomy performed in our series. The incidence of SS after LSG had yearly variations (Fig. 4) and it was higher in the revisional bariatric surgery group, $10 \%(8 / 80)$.

Other 4 patients with SS after LSG, referred at our hospital have been added to the current analysis. As a result, the present study included 51 patients with SS treated in our hospital within the mentioned period. The demographic data of the studied cohort is presented in Table 1 . The average age was $42 \pm 12$ years and the preoperative body mass index (BMI) was 38

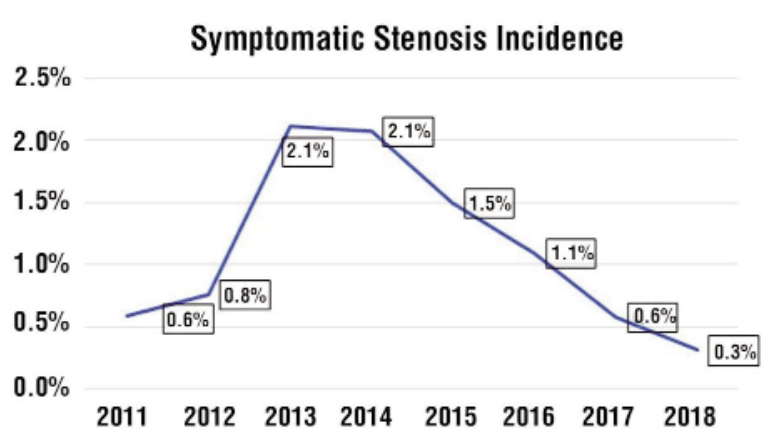

Figure 4. Incidence of SS after LSG 
Table 1. Patient demographics

\begin{tabular}{lc}
\hline Female & $39(23.5 \%)$ \\
\hline Male & $12(76.5 \%)$ \\
\hline Mean age & $47.6 \pm 10.2$ years \\
\hline Body mass index & $38.6 \pm 7.8 \mathrm{~kg} / \mathrm{m}^{2}$ \\
\hline Revisional bariatric surgery & $10(19.6 \%)$ \\
\hline Posterior fixation (PF) & $33(64.7 \%)$ \\
\hline Staple line over-sewing \& PF & $34(66.6 \%)$ \\
\hline Associated other interventions & $32(62.7 \%)$ \\
\hline Time Interval from LSG to SS & \\
\hline Median & 55 days \\
\hline Early presentation (<3 months) & $31(60.8 \%)$ \\
\hline Late presentation (>3 months) & $20(39.2 \%)$ \\
\hline Mean duration of follow-up & $21.5 \pm 10.7$ months \\
\hline
\end{tabular}

$\pm 11 \mathrm{Kg} / \mathrm{m}^{2}$. Ten cases $(19.6 \%)$ were revisional bariatric surgery: five after laparoscopic gastric banding and five after LSG. In 32 patients $(62.7 \%)$ other surgical procedures were associated: 30 hiatal hernia repair (30) and gynecologic procedures (2).

An organic stenosis was identified in 34 cases, being associated with: LSG leaks or abscess (6 patients), "too tight" re-sleeve (4 patients), mediastinal migration of the cardia (4 patients), "too tight" approximation of the crura for HHR (1 patient), intramural hematoma after over-sewing (18 patients), unproper posterior fixation (1 patient), hand sewn gastric fashioning after stapler misfiring (1 patient)

The etiology of functional SS after LSG was associated with incisura angularis obstruction (17 patients), axial twist of the gastric tube (3 patients) and small bowel volvulus (one patient) (Table 2).

Surgery was the first option to treat SS after LAG in nine patients (17.6\%). Early surgical reintervention $(<72 \mathrm{~h})$ for SS was decided in 6 patients (11.7\%):

- One small bowel volvulus was solved by laparoscopic adesiolysis.

- Three acute mediastinal migrations of the upper sleeve through the diaphragmatic hiatus needed the repositioning and fixation of the gastric tube. One of these three, required further endoscopic pneumatic dilation while the other 2 were out of symptoms.
Table 2. Etiology of SS after LSG

\begin{tabular}{ll}
\hline Organic & $\mathbf{3 4}(\mathbf{6 6 . 6 \% )}$ \\
\hline Intramural hematoma & $18(35.3 \%)$ \\
\hline LSG leaks or abscess & $6(11.7 \%)$ \\
\hline "Too tight" re-sleeve & $4(7.8 \%)$ \\
\hline Cardia migration & $4(7.8 \%)$ \\
\hline "Too tight" HHR & $1(1.9 \%)$ \\
\hline Unproper posterior fixation & $1(1.9 \%)$ \\
\hline Hand sewn after stapler misfiring & $1(1.9 \%)$ \\
\hline Functional & $\mathbf{1 7 ( 3 3 . 3 \% )}$ \\
\hline Incisura angularis obstruction & $13(25.5 \%)$ \\
\hline Axial twist of the gastric tube & $3(5.8 \%)$ \\
\hline Small bowel volvulus & $1(1.9 \%)$ \\
\hline
\end{tabular}

- In 2 cases of twisted gastric tube aiming to undo the obstructive over sewing or PF. Both patients needed further endoscopic pneumatic dilation for SS recurrence after surgery.

There were three (5.9\%) late reinterventions (> 3 month) for SS:

- one repositioning and fixation of the gastric tube for mediastinal migration of the upper sleeve, which was latter referred for endoscopic pneumatic dilation and

- two sero-myotomies for gastric stenosis at the incisura angularis, both with unsatisfactory result and revised latter to a Roux en Y Gastric Bypass.

No SS surgical patient was lost from follow-up. Over all, surgery alone resolved the SS condition only in $33.3 \%$ of the cases (3/9).

The demographics of the 46 patients referred to endoscopy are in Table 3. From this endoscopic group, $10(21.7 \%)$ patients had previously performed laparoscopic reinterventions: 6 for stapled line leakage with abscess and/or fistula, 2 for mediastinal migration of the cardia and 2 for twisted gastric tube. In $3(6.5 \%)$ cases the digestive fistula was still active.

The time from LSG to the first endoscopic treatment was 6.9 months, range 18 days to 82 months, with $61 \%$ of the cases in the first 3 months.

A total of 79 endoscopic procedures, 45 using achalasia balloons ( 33 of $30 \mathrm{~mm}, 10$ of 35 
Table 3. Endoscopic approach, patient demographics

\begin{tabular}{lc}
\hline Female & $36(78.2 \%)$ \\
\hline Male & $10(21.8 \%)$ \\
\hline Mean age & $47.3 \pm 10.5$ years \\
\hline Body mass index & $38.6 \pm 7.8 \mathrm{~kg} / \mathrm{m}^{2}$ \\
\hline Revisional bariatric surgery & $9(19.5 \%)$ \\
\hline Posterior fixation & $31(67.3 \%)$ \\
\hline Staple line over-sewing & $31(67.3 \%)$ \\
\hline Associated interventions & $29(63 \%)$ \\
\hline Previous reintervention & $10(21.7 \%)$ \\
\hline Interval since LSG & 59 days \\
\hline Median & $28(60.8 \%)$ \\
\hline Early presentation & $18(39.2 \%)$ \\
\hline Late presentation & $21.5 \pm 10.7$ months \\
\hline Mean duration of follow-up
\end{tabular}

$\mathrm{mm}$ and 2 of $40 \mathrm{~mm}$ ) and 34 using throughthe-scope balloons were performed, resulting in $1.7 \pm 1.1$ procedures per patient (range 1-6). We have encountered 1 complication during the procedure: perforation resolved promptly with fistulo-jejunostomy. No hemorrhage or death were encountered.

Three unsatisfactory results after endoscopic dilation were recorded:

- 2 patients with an active gastro-cutaneus fistula were solved by a fistulo-jejunostomy; one of them had a SEMS placement before the surgery, without successful outcome.

- One patient with migration of the cardia through a "too narrow" diaphragmatic hiatus which was surgically solved (laparoscopic re-approximation of the crura and Narbona_Arnau procedure).

We have lost 3 patients for the post-interventional endoscopy follow-up, resulting in 93.5\% (43/46) follow-up rate. The endoscopic therapy for SS after LSG was successful in $90,7 \%$ of the patients $(39 / 43)$.

Over all, the endoscopic dilation was successful in $90.7 \%$ (39/43) of the patients.

In functional stenosis with:

- An average of $1.3 \pm 0.6$ procedures per patient (range 1-3) were used for the functional stenosis with a success rate of $100 \%(15 / 15)$.

- An average of $1.8 \pm 1.3$ procedures per patient (range 1-6) was performed in organic stenosis, and the success rate was $85.7 \%(24 / 28)$

The success rate was lower $(66.6 \%)$ for the 6 patients presenting LSG complicated with fistula or abscess and an average $2.8 \pm 1.7$ procedures (range 1-6) per patient were necessary. Two out of the 3 cases with active gastric fistula needed fistula-jejunostomy. The third one was solved endoscopically by balloon dilation and OVESCO clip placement.

\section{Discussions}

Laparoscopic sleeve gastrectomy (LSG) has been increased in popularity as an efficient metabolic surgery procedure. Moreover, LSG has proven a low rate of associated postoperative complications. One of these complications is the Symptomatic Stenosis (SS).

The proposed therapeutic solutions for SS are observations and nutritional support, endoscopic procedures (dilation with throughthe-scope balloons, achalasia balloons or selfexpandable stents) $(4,5)$ and surgery including laparoscopic seromyotomy (6) or conversion to gastric by-pass (7).

In this study, we aimed to analyze the incidence and the evolution of SS after LSG relative to the surgical technique modifications and to identify an efficient management for these postoperative complications.

The incidence of SS after LSG may vary with the expertise and the volume of the bariatric center and it ranges between $0.1 \%$ and 3.5\% (Table 4). In our hospital, designated as center of excellence for bariatric surgery, a high- volume of bariatric operations are yearly performed. In this institution, despite targeting to create a low volume gastric sleeve $(60-80 \mathrm{ml})$ by using a $35 \mathrm{Fr}$ calibrating bougie and entirely over-sewing the stapled line, a low incidence of SS is demonstrated. However, the yearly incidence of SS after LSG rose in 2013 and 2014 when we have introduced the posterior fixation the gastric tube (PF) and the over-sewing of the entire stapled line, respectively (Fig. 4).

The rationale of introducing the posterior fixation (PF) of the stapled line in LSG was 
Table 4. The incidence of SS after LSG

\begin{tabular}{lcccc}
\hline author & year & nr. & SS & incidence \\
\hline Dhorepatil (4) & 2018 & 1756 & 33 & 1.88 \\
\hline Desalauries (11) & 2018 & 1332 & 27 & 2.00 \\
\hline Al Sabah (12) & 2017 & 2500 & 26 & 1.04 \\
\hline Rebibo (13) & 2016 & 1210 & 17 & 1.40 \\
\hline Ogra (14) & 2015 & 857 & 26 & 3.03 \\
\hline Burgos (15) & 2013 & 717 & 5 & 0.70 \\
\hline Vilallonga (6) & 2013 & 812 & 16 & 1.97 \\
\hline Boza (16) & 2012 & 1,000 & 1 & 0.10 \\
\hline Parikh (5) & 2011 & 230 & 8 & 3.48 \\
\hline Lacy (17) & 2010 & 294 & 3 & 1.02 \\
\hline Present study & 2018 & 4304 & 47 & 1.09 \\
\hline TOTAL & & 13680 & 182 & 1.33 \\
\hline
\end{tabular}

based on the observation that, although the uniform fashioning of the "L" shaped gastric tube, in a significant number of the cases, an axial twist or a functional obstruction at the incisura angularis was encountered $(9,10)$.

$\mathrm{PF}$ has immediately proven its efficiency and, as a consequence, a very reduced number of functional obstructions due to gastric sleeve inadequate geometry were encountered. More organic stenosis after sleeve then the functional ones were identified in our series.

Moreover, the over-sewing of the entire stapled line, aiming to prevent the postoperative stapled line bleeding was introduced in 2014. This technical modification of LSG had determined some specific complications related to the difficult technique of placing a running suture along a very long stapled line. A relative high number of gastric wall hematomas causing SS (23) is explained by the difficult of avoiding vessels injuries during the running suture, especially in the patients with central obesity and a consistent visceral fat. A "too tight" gastric tube or an obstructing parietal hematoma can be linked to the learning curve of the over-sewing of the stapler line. Indeed, a very long learning curve for the over-sewing the stapled line was then-after demonstrated (Fig. 5), requiring many hundreds of procedures to reduce back the SS incidence.

As expected, when laparoscopic sleeve resections were used for revisional surgery the incidence if SS was much higher, 10 time more than the primary LSG. A "too narrow" gastric tube created at the time of the re-sleeve was one of the most frequent causes of SS in this series.

In all the patients with radiologically confirmed SS after LSG in which there is no improvement after conservative treatment, laparoscopic or endoscopic procedures are to be considered, depending to the particular situation of each patient.

It is already demonstrated that, any obstruction that affects the LSG emptying and increases the intragastric pressure can favor the occurrence of the stapled line leak and fistula. On the other hand, the perigastric collections/abcesses are risk factors for stenosis and there is no chance for the leak to close if the distal stenosis with not be solved. Interventional endoscopy should be the first line in these cases, starting with balloon dilatations and stents (SEMS)(14).

Revisional surgery (RYGBP or fistulajejunostomy) should be considered whereas the failure of endoscopic therapy is demonstrated.

Symptomatic stenosis caused by the acute migration of the cardia through the diaphragmatic hiatus, after LSG with an associated hiatal hernia repair, remains in our opinion an indication for the immediate surgical reintervention. In these instances, a functional obstruction (kinking of the stomach) is combined with an organic one, the limited space inside of the hiatus. Therefore, we consider mandatory to identify the position of the GEJ in any SS after LSG, either by fluo-

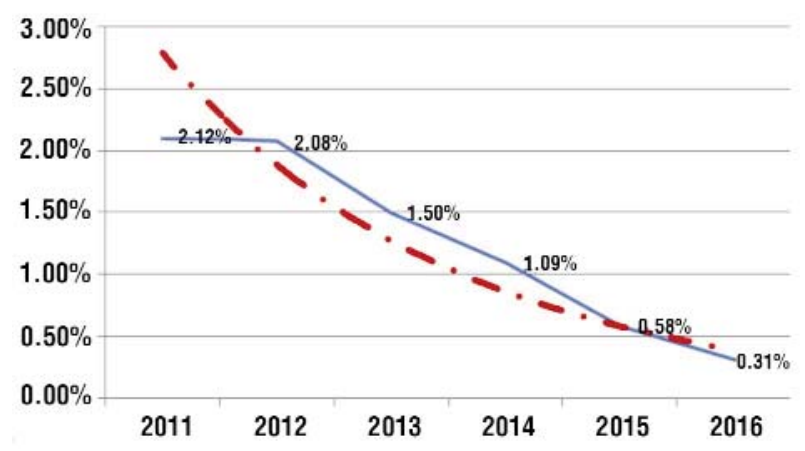

Figure 5. Learning curve for avoiding SS after LSG 
roscopy, spotting the metallic clips placed on the top of the stapled line or by using a CTscan with $3 \mathrm{D}$ reconstruction of the stomach. The surgical repositioning and intra-abdominal fixation of the gastric tube are to be performed before any ischemic or severe septic complications (mediastinitis) are installed.

Beside these acute cases, surgery had an unexpected low rate of success (overall $33.3 \%)$. In our series, the laparoscopic seromyotomy was used in two cases but, apart from the technical challenges of the procedure, the postoperative, and the postoperative functional results were very poor and we do not recommend it anymore. Same modest outcomes are reported by Vilallonga (6). In a series of 14 seromiotomies, $5(35.7 \%)$ developed a leak, $3(21.4 \%)$ patients required conversion to gastric bypass and other $3(21.4 \%)$ were referred to endoscopy.

The surgical laparoscopic approach, as Roux en Y Gastric Bypass or fistulojejunoanastomosis are very efficient options for special cases of SS after LSG associated with fistula or severe obstruction but they should be used only in case of the endoscopic procedures' failure.

The endoscopic approach is safe. We have encountered only one perforation that means $2.1 \%$ from all the patients and $1.2 \%$ from all the endoscopic procedures. The endoscopic approach was very effective in our series, similar to the data reported in the literature (Table 5).

In our experience functional stenosis respond very well to pneumatic dilation. With an average $1.3 \pm 0.6$ procedures the success rate was $100 \%$.

Good results were noted in $85.7 \%$ of the organic stenosis with an average $1.8 \pm 1.3$ procedures per patient. The difference between these two fundamentally different obstructive patterns may explain the variability of response to pneumatic dilatation.

If we also approached 6 cases of LSG complicated with fistula or abscess and in these cases, as expected, the success rate was lower $66.6 \%$ with an average $2.8 \pm 1.7$ procedures per patient. In one of the failed
Table 5. Effectiveness of the endoscopic approach

\begin{tabular}{lcccc}
\hline author & year & nr. & morbidity & Success \\
\hline Dhorepatil (4) & 2018 & 33 & 0 & $31(94 \%)$ \\
\hline Desalauries (11) & 2018 & 27 & 1 & $15(55 \%)$ \\
\hline Al Sabah (12) & 2017 & 26 & 1 & $23(88 \%)$ \\
\hline Manos (18) & 2017 & 18 & 1 & $17(94 \%)$ \\
\hline Donatelli (19) & 2017 & 33 & 2 & $20(61 \%)$ \\
\hline Agnihotri (20) & 2017 & 17 & 1 & $15(88 \%)$ \\
\hline Nath (21) & 2016 & 33 & 0 & $23(70 \%)$ \\
\hline Rebibo (13) & 2016 & 17 & 0 & $15(88 \%)$ \\
\hline Ogra (14) & 2015 & 26 & 1 & $26(100 \%)$ \\
\hline Baretta (22) & 2015 & 13 & 2 & $13(100 \%)$ \\
\hline Shnell (23) & 2014 & 16 & 0 & $7(44 \%)$ \\
\hline Burgos (15) & 2013 & 5 & 0 & $4(80 \%)$ \\
\hline Parikh (5) & 2011 & 10 & 1 & $8(80 \%)$ \\
\hline Present study & 2018 & 43 & 1 & $39(90.7 \%)$ \\
\hline TOTAL & & 320 & 11 & $256(80 \%)$ \\
\hline
\end{tabular}

cases, we have useda self-expandable metallic stent (SEMS) but the result was not satisfactory (Fig. 5). The SEMS was explanted after 3 weeks and no improvement of the gastric flow was demonstrated. Finaly, the patient underwent revisional surgery and a laparoscopic Roux en Y fistula-jejuno-anastomosis was performed with very good results.

The literature is scarce on this subject. Ogra (14) has used it in 5 cases with success ( 1 migration), Al Sabah (12) in 2 cases without success (1 migration), Parikh (5) in 2 cases without success (1 migration). Eubanks (24) has used self expandable stents in 19 cases to treat acute leakage, gastrocutaneous fistula or strictures after bariatric surgery. A common problem was the migration of the stent, who occurred in $58 \%$ of 34 stents placed. As regarding strictures he report good results in 5 out of 6 cases. To prevent migration Agnihotri (20) use short nitinol stents secured in place with an endoscopic suturing system (OverStitch, Apollo Endosurgery).

The follow-up rate in our series is $93.5 \%$, as we have lost only 3 patients for further evaluations, with an average of $21.5 \pm 10.7$ month. However, 34 patients did not have any recurrency after the endoscopic therapy for more than one year, proving that pneumatic dilation of the strictures are durable.

On our experience it is obvious that 
endoscopic procedure is a very good option, with low morbidity and with rare exceptions (acute mediastinal migrations) should be the first choice in treating SS after LSG that do not improve after conservative treatment.

We consider that one of our study's strengths is related to the high-volume activity of a single bariatric surgery center of excellence where rigorous data collection is prospectively maintained. By analyzing a large homogenous cohort of patients undergoing LSG, a very low incidence of symptomatic stenosis was demonstrated. Nevertheless, the introduction of the stapled line over-sewing in the surgical protocol for LSG may have a significant impact on postoperative complications. We were also able to present evidence that, after overcoming a long learning curve, the stapled line over-sewing and posterior fixation $\mathrm{PF}$ were not increasing the obstruction rate after LSG, as it was stated in the literature. Our study confirm the data from literature and supports the usage of endoscopic dilatations as the first line therapy for most of the SS after LSG.

The main limitations of our study are its retrospective and noncomparative condition of a relative small sample sized population presenting SS after LSG. Moreover, no data on the symptomatic stenosis and its treatment's (surgical or endoscopic) influence on bariatric surgery efficiency (BMI evolution, hospital stay) was calculated.

\section{Concluding Remarks}

The incidence of SS after LSG is very low with a higher rate for revisional surgery. The stapled line over-sewing techniques may have a long learning curve with a significant initial impact on postoperative obstructive complication rate.As the experience is gained, the stapled line over-sewing and posterior fixation $\mathrm{PF}$ are not increasing the obstruction rate after LSG.

Endoscopic procedures should be offered from the diagnosis of SS after LSG and rely on endoscopic dilatation with through-the scope balloons or achalasia over-the-wire balloons. Pneumatic endoscopic dilatation for stenosis after LSG is effective, safe and durable.

Endoscopic alternatives to surgery like stent placement have to be further explored.

Surgery should be limited to emergency cases and failures after endoscopic techniques.

\section{Conflict of Interest}

The authors declare no conflicts of interests.

\section{Author's Contributions}

All authors contributed equally to the article.

\section{References}

1. Khorgami Z, Andalib A, Corcelles R, Aminian A. Recent national trends in the surgical treatment of obesity: sleeve gastrectomy dominates. Surg Obes Relat Dis. 2015 11(6):S6-S8

2. Sarkhosh K, Birch DW, Sharma A, Karmali S. Complications associated with laparoscopic sleeve gastrectomy for morbid obesity: a surgeon's guide. Can J Surg. 2013;56(5):347-52.

3. Kumar SB, Hamilton BC, Wood SG, Rogers SJ, Carter JT, Lin MY. Is laparoscopic sleeve gastrectomy safer than laparoscopic gastric bypass? a comparison of 30-day complications using the MBSAQIP data registry. Surg Obes Relat Dis. 2018;14(3): 264-269.

4. Dhorepatil AS, Cottam D, Surve A, Medlin W, Zaveri H, Richards C, et al. Is pneumatic balloon dilation safe and effective primary modality of treatment for post-sleeve gastrectomy strictures? A retrospective study. BMC Surg. 2018;18(1):52.

5. Parikh A, Alley JB, Peterson RM, Harnisch MC, Pfluke JM, Tapper DM, et al. Management options for symptomatic stenosis after laparoscopic vertical sleeve gastrectomy in the morbidly obese. Surg Endosc. 2012;26(3):738-46.

6. Vilallonga R, Himpens J, van de Vrande S. Laparoscopic management of persistent strictures after laparoscopic sleeve gastrectomy. Obes Surg. 2013;23(10):1655-61.

7. Landreneau J, Strong A, H. Rodriguez J, Aleassa E, Aminian A, Brethauer S, et al. Conversion of Sleeve Gastrectomy to Roux-enY Gastric Bypass. Obes Surg. 2018;28(12):3843-3850.

8. Copaescu C. Laparoscopic sleeve gastrectomy for morbid obesity. Chirurgia (Bucur). 2009;104(1):79-85

9. Abd Ellatif ME, Abbas A, El Nakeeb A, Magdy A, Salama AF, Bashah MM, et al. Management Options for Twisted Gastric Tube after Laparoscopic Sleeve Gastrectomy. Obesity surgery. 2017;27(9): 2404-9.

10. Shnell M, Fishman S, Eldar S, Goitein D, Santo E. Balloon dilatation for symptomatic gastric sleeve stricture. Gastrointestinal Endoscopy. 2014;79(3):521-4.

11. Deslauriers V, Beauchamp A, Garofalo F, Atlas H, Denis R, Garneau $P$, et al. Endoscopic management of post-laparoscopic sleeve gastrectomy stenosis. Surg Endosc. 2018;32(2):601-609.

12. Al Sabah S, Al Haddad E, Siddique I. Endoscopic management of post-laparoscopic sleeve gastrectomy stenosis. Surg Endosc. 2017;31(9):3559-3563.

13. Rebibo L, Hakim S, Dhahri A, Yzet T, Delcenserie R, Regimbeau JM. Gastric Stenosis After Laparoscopic Sleeve Gastrectomy: Diagnosis and Management. Obes Surg. 2016;26(5):995-1001.

14. Ogra R, Kini GP. Evolving endoscopic management options for symptomatic stenosis post-laparoscopic sleeve gastrectomy for 
morbid obesity: experience at a large bariatric surgery unit in New Zealand. Obes Surg. 2015;25(2):242-8

15. Burgos AM, Csendes A, Braghetto I. Gastric stenosis after laparos copic sleeve gastrectomy in morbidly obese patients. Obes Surg. 2013;23:1481-6.

16. Boza C, Salinas J, Salgado N, Pérez G, Raddatz A, Funke R, et al. Laparoscopic sleeve gastrectomy as a stand-alone procedure for morbid obesity: report of 1,000 cases and 3-year follow-up. Obes Surg. 2012;22(6):866-71.

17. Lacy A, Ibarzabal A, Pando E, Adelsdorfer C, Delitala A, Corcelles R, et al. Revisional surgery after sleeve gastrectomy. Surg Laparosc Endosc Percutan Tech. 2010;20(5):351-6.

18. Manos T, Nedelcu M, Cotirlet A, Eddbali I, Gagner M, Noel P. How to treat stenosis after sleeve gastrectomy? Surg Obes Relat Dis. 2017:13(2):150-154.

19. Donatelli G, Dumont JL, Pourcher G, Tranchart H, Tuszynski T, Dagher I, et al. Pneumatic dilation for functional helix stenosis after sleeve gastrectomy: long-term follow-up (with videos). Surg Obes Relat Dis. 2017;13(6):943-950.
20. Agnihotri A, Barola S, Hill C, Neto MG, Campos J, Singh VK, et al. An Algorithmic Approach to the Management of Gastric Stenosis Following Laparoscopic Sleeve Gastrectomy. Obes Surg. 2017; 27(10):2628-2636

21. Nath A, Yewale S, Tran T, Brebbia JS, Shope TR, Koch TR. Dysphagia after vertical sleeve gastrectomy: evaluation of risk factors and assessment of endoscopic intervention. World $\mathrm{J}$ Gastroenterol. 2016;22(47):10371-10379.

22. Baretta G, Campos J, Correia S, Alhinho H, Marchesini JB, Lima JH, et al. Bariatric postoperative fistula: a life-saving endoscopic procedure. Surg Endosc. 2015;29(7): 1714-20

23. Shnell M, Gluck N, Abu-Abeid S, Santo E, Fishman S. Use of endoscopic septotomy for the treatment of late staple-line leaks after laparoscopic sleeve gastrectomy. Endoscopy. 2017;49(1): 59-63.

24. Eubanks S, Edwards CA, Fearing NM, Ramaswamy A, de la Torre $\mathrm{RA}$, Thaler KJ, et al. Use of endoscopic stents to treat anastomotic complications after bariatric surgery. J Am Coll Surg. 2008;206(5): 935-8; discussion 938-9. 